\title{
Total Synthesis of Mycalolides A and B via Olefin Metathesis **
}

\author{
Masaki Kita,* Hirotaka Oka, Akihiro Usui, Tomoya Ishitsuka, Yuzo Mogi, Hidekazu Watanabe, Masaki \\ Tsunoda, and Hideo Kigoshi *
}

\begin{abstract}
An asymmetric total synthesis of the tris-oxazole marine macrolides, mycalolides $A$ and $B$ is described. This synthesis involves the convergent assembly of highly functionalized C1-C19 tris-oxazole and C20-C35 side-chain segments through the use of olefin metathesis and esterification, as well as Julia-Kocienski olefination and enamide formation as key steps.
\end{abstract}

Mycalolides are cytotoxic and antimycotic tris-oxazole macrolides, which was isolated from the marine sponge Mycale sp. ${ }^{[1]}$ They inhibit actomyosin $\mathrm{Mg}^{2+}-$ ATPase ${ }^{[2]}$ and show potent actin-depolymerizing activity by forming a 1:1 complex with monomeric molecule. ${ }^{[3]}$ Mycalolide B (1) contains a 2,3-Odimethyl-D-glyceryl ester moiety and 13 asymmetric centers as structural features, while a closely related mycalolide A (2) contains a ketone functionality at C30. Several tris-oxazole macrolides that are closely related to mycalolides have been isolated, such as ulapualides, ${ }^{[4]}$ halichondramides, ${ }^{[5]}$ jaspisamides, ${ }^{[6]}$ and kabiramides; ${ }^{[7]}$ all of these exhibit actindepolymerizing activity and potent cytotoxicity, and some induce apoptosis in tumor cells. ${ }^{[8]}$ Thus, these agents may be useful for the design and development of novel pharmacological tools for analyzing actin-mediated cell functions, such as muscle contraction, cell motility, and cytokinesis, as well as those of therapeutic agents. ${ }^{[9]}$

Mycalolides can be divided into two structurally characteristic parts: the $\mathrm{C} 1-\mathrm{C} 24$ tris-oxazole macrolactone and the $\mathrm{C} 25-\mathrm{C} 35$ side-chain functionalized by $\mathrm{N}$-methyl enamide moiety. Studies on the structure-activity relationships ${ }^{[10]}$ and photolabeling experiments ${ }^{[11]}$ have established that the sidechain part of mycalolides is important for its ability to bind to and depolymerize actin. In addition, X-ray analyses of the actinkabiramide $C,{ }^{[12]}$ actin-jaspisamide $A,{ }^{[12]}$ and actin-ulapualide $A$ complexes [13] have revealed that their side-chain parts intercalate into the hydrophobic cleft between subdomains 1 and 3 of actin. Meanwhile, we recently synthesized the $19 E-$ and 19Z-lactone analogs of mycalolides that lack the C25-C35 sidechain; these analogs exhibited moderate cytotoxicity against

[*] Prof. Dr. M. Kita, H. Oka, A. Usui, T. Ishitsuka, Y. Mogi, H. Watanabe, M. Tsunoda, Prof. Dr. H. Kigoshi Graduate School of Pure and Applied Sciences University of Tsukuba

1-1-1 Tennodai, Tsukuba 305-8571 (Japan) Fax: (+81) 29-853-4313

E-mail: mkita@chem.tsukuba.ac.jp; kigoshi@chem.tsukuba.ac.jp

[**] We thank Prof. Shigeki Matsunaga (The University of Tokyo) for providing natural mycalolide B. This work is supported in part by JSPS grants (25702047 to M.K. and 26242073 to H.K.) and by a Grant-in-Aid for Scientific Research on Innovative Areas from MEXT, Japan, "Chemical Biology of Natural Products." Support was also provided by the Naito Foundation. We thank Maiko Matsuki for preparation of $\mathbf{7}$, and Toru Watanabe and Shun Watanabe for preparation of precursors of 3 .

Supporting information for this article is available on the WWW under http://dx.doi.org/10.1002/anie?? tumor cells (ca. 1/100 of 1), but did not show actindepolymerizing properties or antimycotic activity against pathogenic fungi. ${ }^{[14]}$ Thus, both the side-chain and macrolactone moieties were suggested to be essential for the potent biological activities of the parent molecules.

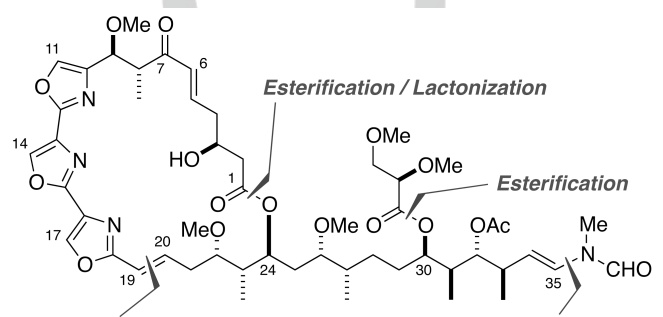

RCM / Cross metathesis Mycalolide B (1) Enamide formation

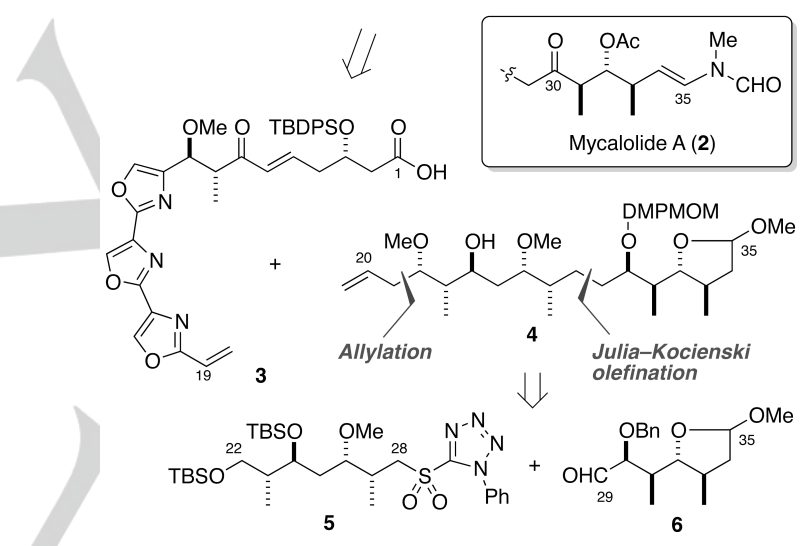

Scheme 1. Strategies for the synthesis of mycalolides A and B.

Due to their extraordinary structures and biological activities, mycalolides and their congeners have received considerable attention in the synthetic community, and several approaches to the construction of conformationally-restricted tris-oxazole macrolactone structures have been described. ${ }^{[15]}$ To date, total syntheses of mycalolide $A(2)^{[16]}$ and ulapualide $A^{[17]}$ have been accomplished, in which Yamaguchi lactonization, cyclization of the central oxazole ring, or intramolecular HornerWadsworth-Emmons olefination were used to construct macrocycles. However, no total synthesis of mycalolide B has been disclosed to date. We describe here the first total synthesis of (-)-mycalolide B (1) and the second synthesis of mycalolide $A$ (2) through the use of olefin metathesis as a key step.

Based on the finding that olefin metathesis is a useful method for connecting the C19-C20 double bonds in mycalolide analogs, ${ }^{[10 \mathrm{c}, 18]}$ we designed a plan for the synthesis of 1 (Scheme 1). After disconnection of the C35 N-methyl enamide moiety and the C30 ester bond, the macrolactone structure of 1 could be divided into a C1-C19 tris-oxazole segment 3 and a C20-C35 side-chain segment 4. We expected that the convergent assembly of $\mathbf{3}$ and $\mathbf{4}$ via esterification / ring-closing metathesis (RCM) would efficiently afford a key macrolactone. 
Instead, cross metathesis of $\mathbf{3}$ and $\mathbf{4}$, in which the carboxyl or hydroxyl groups are protected, and subsequent macrolactonization could also provide the same intermediate. While the side-chain segment $\mathbf{4}$ was previously synthesized, ${ }^{[10,18]}$ in this study we planned to modify the synthetic route, which includes the Julia-Kocienski olefination ${ }^{[19]}$ between phenyl tetrazole (PT)-sulfone $\mathbf{5}$ and aldehyde $\mathbf{6}$.

Our synthesis started with the preparation of $\mathbf{5}$ (Scheme 2). Methylation of the known syn-aldol $7^{[10 \mathrm{~b}]}$ with methyl trifluoromethanesulfonate (MeOTf) and removal of the chiral auxiliary with $\mathrm{LiBH}_{4}$ yielded primary alcohol $\mathbf{8}$. Conversion of 8 into the $\mathrm{PT}$-sulfide with aryl disulfide/ $\mathrm{Bu}_{3} \mathrm{P}$ and subsequent oxidation with $m$-CPBA yielded PT-sulfone 5 .
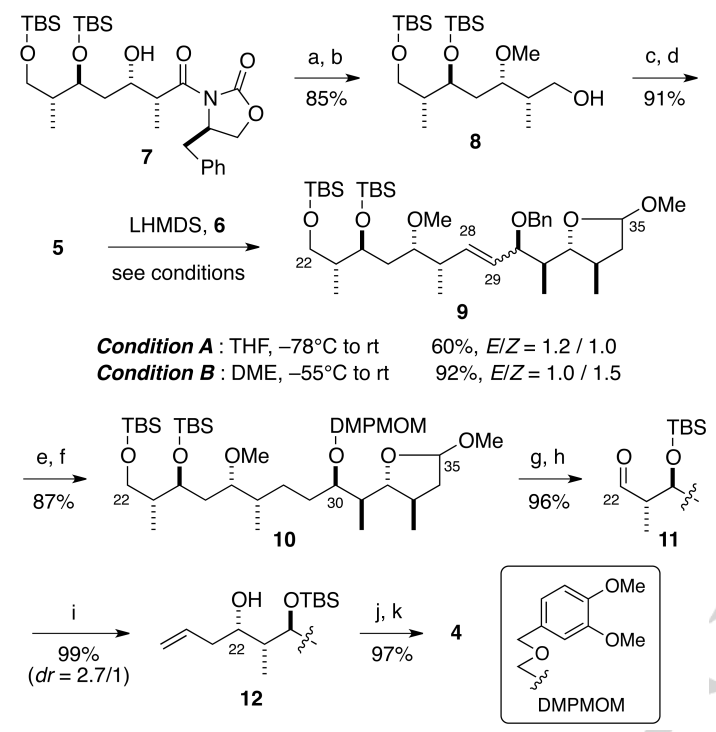

Scheme 2. Synthesis of the $\mathrm{C} 20-\mathrm{C} 35$ segment 4. Reagents and conditions: a) MeOTf, 2,6-di-tert-butylpyridine, $\mathrm{CH}_{2} \mathrm{Cl}_{2}$; b) $\mathrm{LiBH}_{4}$, EtOH, $\mathrm{Et}_{2} \mathrm{O}-\mathrm{THF}$, $-10{ }^{\circ} \mathrm{C}$; c) $5,5^{\prime}$-dithiobis(1-phenyl- $1 \mathrm{H}$-tetrazole), tri- $n$-butylphosphine, THF; d) $m$ CPBA, $\mathrm{NaHCO}_{3}, \mathrm{CH}_{2} \mathrm{Cl}_{2}$; e) $\left.\mathrm{H}_{2}, \mathrm{Pd}(\mathrm{OH})_{2} / \mathrm{C}(20 \mathrm{~mol} \%), \mathrm{NaHCO}_{3}, \mathrm{EtOH} ; \mathrm{f}\right)$ 3,4-dimethoxybenzyloxymethyl chloride, i- $\mathrm{Pr}_{2} \mathrm{NEt}, \mathrm{CH}_{2} \mathrm{Cl}_{2}$; g) $\mathrm{NH}_{4} \mathrm{~F}, \mathrm{MeOH}$, $40{ }^{\circ} \mathrm{C}$; h) Dess-Martin periodinane, pyridine, $\mathrm{CH}_{2} \mathrm{Cl}_{2}$; i) $\mathrm{CH}_{2}=\mathrm{CHCH}_{2} \mathrm{MgBr}$, THF-Et ${ }_{2} \mathrm{O}$; j) Mel, NaH, THF; k) ${ }^{n} \mathrm{Bu}_{4} \mathrm{NF}$, THF, rt to $40^{\circ} \mathrm{C}$.

Next, Julia-Kocienski coupling was examined. Despite the sterically hindered, branched structures of both starting materials, treatment of $\mathbf{5}$ with LHMDS followed by the addition of aldehyde $6^{[20]}$ in THF at $-78{ }^{\circ} \mathrm{C}$ afforded olefin 9 in $60 \%$ yield (condition $A, E / Z=1.2 / 1$ ). After several attempts, the yield was improved to $92 \%$ (condition $B, E / Z=1 / 1.5$ ) with the use of the same base in 1,2-dimethoxyethane (DME) at $-55{ }^{\circ} \mathrm{C}$ to room temperature. While an excess amount of PT-sulfone 5 ( 2.5 eq.) was required to complete the reaction, this material was recovered quantitatively and reused.

Catalytic hydrogenation of the $\mathrm{C}=\mathrm{C}$ double bond and hydrogenolysis of the benzyl group from the E/Z-mixture of $\mathbf{9}$ proceeded concurrently with palladium (II) hydroxide on carbon. Subsequent protection of the C30 hydroxy group as a 3,4dimethoxyphenylmethoxymethyl (DMPMOM) group afforded previously synthesized ether $10{ }^{[10 \mathrm{~b}]}$ Selective deprotection of the TBS group in 10 with $\mathrm{NH}_{4} \mathrm{~F}$ and oxidation of the primary alcohol with Dess-Martin periodinane provided aldehyde 11. Grignard reaction of $\mathbf{1 1}$ with allylmagnesium bromide resulted in a mixture of $S$ - and $R$-alcohol $12(d r=2.7 / 1)$, which were separated by column chromatography. ${ }^{[21]}$ Finally, methylation of the secondary alcohol in 22S-12 and deprotection of the remaining TBS group with tetra- $n$-butylammonium fluoride (TBAF) gave the C20-C35 segment 4.

With the side-chain segment $\mathbf{4}$ in hand, we initially considered the RCM approach to reduce unnecessary protection I deprotection steps (Scheme 3). Condensation of the C1-C19 segment $3{ }^{[18]}$ with 4 by the Shiina procedure using 2-methyl-6nitrobenzoic anhydride (MNBA) ${ }^{[22]}$ afforded the RCM precursor 13. We previously reported that treatment of 13 with $30 \mathrm{~mol} \%$ of 2nd-generation Grubbs catalyst (17a) ${ }^{[23]}$ in degassed refluxing toluene led to the decomposition of the starting material (entry 1). ${ }^{[18]}$ However, in refluxing $\mathrm{CH}_{2} \mathrm{Cl}_{2}$, tris-oxazole lactone 15 was obtained as an $E / Z$ mixture $(40 \%, E / Z=1.9: 1$, entry 2$)$, while the reaction did not run to completion.

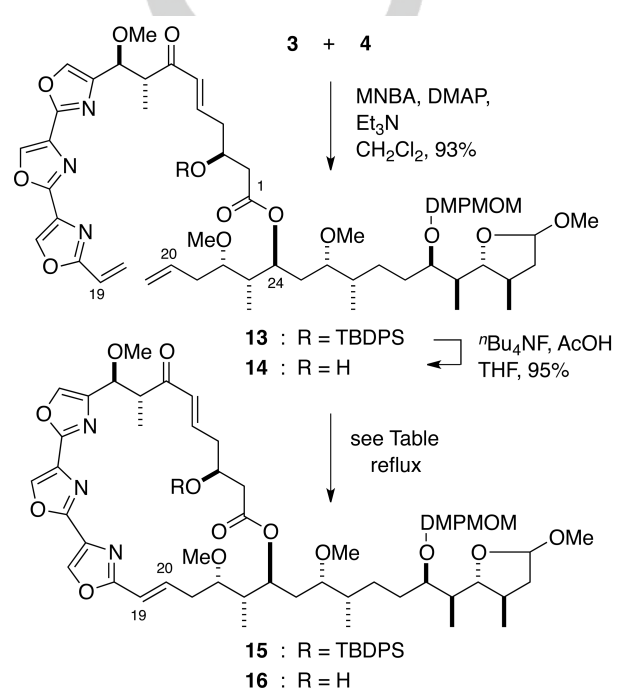

\begin{tabular}{|c|c|c|c|c|c|c|}
\hline \multirow{2}{*}{ entry } & \multirow{2}{*}{ s.m. } & \multirow{2}{*}{$\begin{array}{c}\text { catalyst } \\
\text { (30 mol\%) }\end{array}$} & \multirow{2}{*}{$\begin{array}{c}\text { solvent } \\
(0.9 \mathrm{mM})\end{array}$} & \multirow{2}{*}{ time $(\mathrm{h})$} & \multicolumn{2}{|c|}{ yields (\%) } \\
\hline & & & & & product (19E/19Z) & s.m. recov. \\
\hline $1^{a}$ & 13 & $17 a$ & toluene & 4 & trace & $-{ }^{b}$ \\
\hline 2 & 13 & $17 a$ & $\mathrm{CH}_{2} \mathrm{Cl}_{2}$ & 3 & $40(1.9: 1.0)$ & 31 \\
\hline $3^{a}$ & 13 & $17 b$ & toluene & 3 & $76(1.0: 1.2)$ & - \\
\hline 4 & 13 & $17 \mathrm{~b}$ & $\mathrm{CH}_{2} \mathrm{Cl}_{2}$ & 37 & $37(2.0: 1.0)$ & 40 \\
\hline 5 & 13 & $17 b$ & DCE & 38 & $40(1.0: 1.0)$ & 54 \\
\hline 6 & 13 & $17 \mathrm{c}$ & $\mathrm{CH}_{2} \mathrm{Cl}_{2}$ & 24 & $69(1.6: 1.0)$ & - \\
\hline 7 & 13 & $17 d$ & $\mathrm{CH}_{2} \mathrm{Cl}_{2}$ & 24 & $75(1.7: 1.0)$ & - \\
\hline 8 & 14 & $17 c$ & $\mathrm{CH}_{2} \mathrm{Cl}_{2}$ & 24 & $63(2.7: 1.0)$ & - \\
\hline
\end{tabular}

a See ref. 18.

${ }^{b}$ s. m. was decomposed and not recovered.

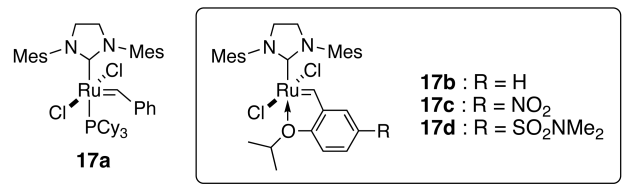

Scheme 3. Synthesis of macrolactones 15 and 16 via ring-closing metathesis

Due to the instability of catalyst $17 a$ for the slow metathesis reaction of macrocycle precursors, we next examined 2nd-generation Hoveyda-Grubbs (HG-II) catalyst (17b). ${ }^{[2]}$ We previously reported that treatment of 13 with 30 mol\% $17 \mathrm{~b}$ in refluxing toluene afforded the RCM product 15 in higher yield but with undesired C19-C20 Z-isomer slightly preferred $(76 \%, E / Z=1 / 1.2$, entry 3$) .{ }^{[18]}$ Meanwhile, in the model $\mathrm{RCM}$ reactions of $\mathrm{C} 1-\mathrm{C} 24$ macrolactone analogs, the solvent polarity was found to significantly affect the stereoselectivity; the 
$Z$-isomer was preferred in $n$-hexane and toluene $(E / Z=$ 1/1.9 2.5), while the $E$-isomer was preferred in $\mathrm{CH}_{2} \mathrm{Cl}_{2}(E / Z=$ $1.8 / 1){ }^{[14]}$ In fact, for the RCM reaction of 13 with $17 \mathrm{~b}$ in refluxing $\mathrm{CH}_{2} \mathrm{Cl}_{2}$, the ratio was improved to $2.0: 1$, but the reaction did not run to completion, similar to the use of 17 a (entry 4 ). These results suggested that the C25-C35 segment in 13 minimally affected the stereoselectivity, but decreased the reactivity for $\mathrm{RCM}$ reactions, probably due to the steric hindrance in forming the ruthenocyclobutane intermediate. Under refluxing conditions in 1,2-dichloroethane (DCE), the stereoselectivity decreased to 1.0:1 (entry 5). To facilitate the initiation of the catalytic cycle at lower temperature, two highly reactive $H G-/ /$ catalyst derivatives 17c (Grela catalyst) ${ }^{[25]}$ and 17d (Zhan catalyst 1B) ${ }^{[26]}$ were examined, in which nitro or $N, N$-dimethylsulfonamide groups are substituted on the 2-isopropoxybenzylidene ligand. Notably, the use of both electron-deficient catalysts similarly increased the yield of 15 to $69-75 \%$, while stereoselectivity was still low $(E / Z=$ 1.6-1.7/1, entries 6 and 7). We expected that such low stereoselectivity of RCM precursor 13 was due to the presence of structurally hindered C3 TBDPS group. For comparison, a C3 hydroxy analog 14 was prepared from 13 by the treatment with TBAF along with acetic acid $(\mathrm{AcOH})$. With the use of catalyst 17c in refluxing $\mathrm{CH}_{2} \mathrm{Cl}_{2}$, the stereoselectivity of $\mathrm{C} 3$ hydroxy macrolactone 16 was improved to $2.7: 1$, but the yield was lower than that of 15 (entry 8).
After the TES group in (E)-20 was removed under mild acidic conditions, the resultant alcohol was treated with activated zinc in acetate buffer to afford seco acid 21. Macrolactonization of 21 by the Yamaguchi procedure ${ }^{[28]}$ readily proceeded to give the lactone 15. Due to the higher stereoselectivity, the cross metathesis-macrolactonization approach was preferred to the RCM approach.

The stage was then set for functionalization of the last side-chain part (Scheme 5). Acidic hydrolysis of the C35 methyl acetal in $\mathbf{1 5}$ afforded hemiacetal 22. Selective reductions of the five-membered hemiacetal in $\mathbf{2 2}$ using conventional hydride reagents were unsuccessful. ${ }^{[2]}$ To our delight, however, Luche reduction of 22 at $-20{ }^{\circ} \mathrm{C}$ exclusively led to 1,2-reduction of the $\mathrm{C} 7$ ketone followed by $\mathrm{C} 35$ hemiacetal reduction at $0{ }^{\circ} \mathrm{C}$ to afford triol 23 quantitatively ( $d r=10: 1$ at $C 7$ ). Next, trityl group protection of the primary alcohol, and chemoselective oxidation of the allylic alcohol with manganese dioxide gave ketone 24 . Subsequent acetylation of the remaining C32 secondary alcohol, removal of the trityl group with formic acid in ether, and oxidation of the primary alcohol with Dess-Martin periodinane gave aldehyde 25. Dehydrating condensation with $\mathrm{N}$ methylformamide under acidic conditions, ${ }^{[30]}$ and deprotection of the DMPMOM group with 2,3-dichloro-5,6-dicyano- $p$ benzoquinone (DDQ) afforded secondary alcohol 26.

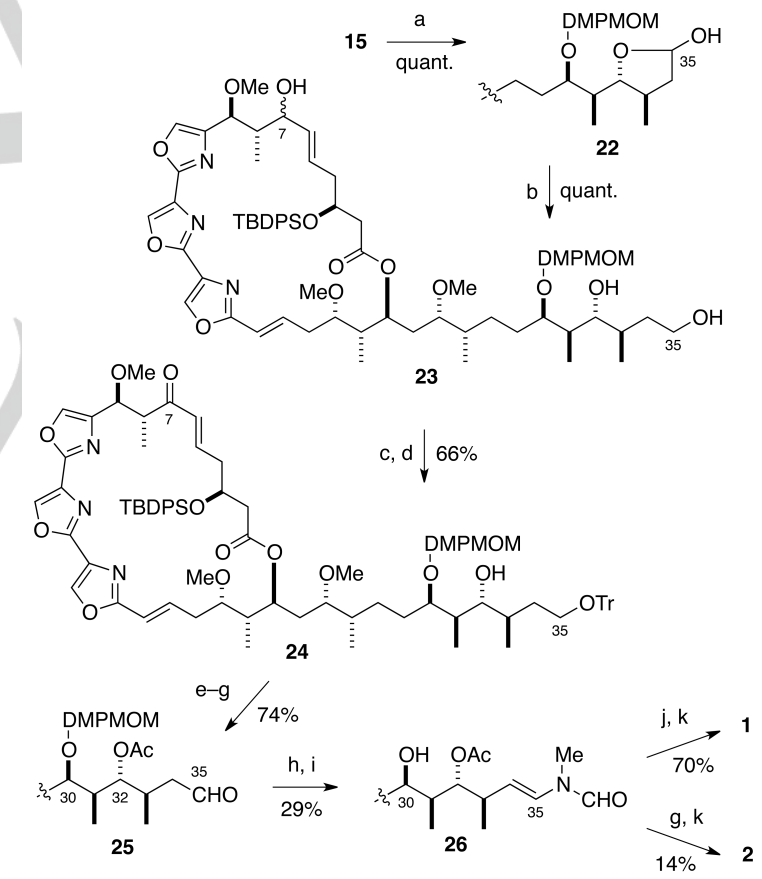

Scheme 5. Synthesis of mycalolides $\mathrm{A}$ and $\mathrm{B}$. Reagents and conditions: a) 1 $\mathrm{M} \mathrm{HCl}$ aq., 1,2-dimethoxyethane; b) $\mathrm{NaBH}_{4}, \mathrm{CeCl}_{3} \cdot 7 \mathrm{H}_{2} \mathrm{O}, \mathrm{MeOH},-20$ to $0{ }^{\circ} \mathrm{C}$; c) $\mathrm{TrCl}$, pyridine; d) $\mathrm{MnO}_{2}, \mathrm{CH}_{2} \mathrm{Cl}_{2}$; e) $\mathrm{Ac}_{2} \mathrm{O}$, DMAP, pyridine; f) $\mathrm{HCOOH}, \mathrm{Et}_{2} \mathrm{O}$; g) Dess-Martin periodinane, pyridine, $\mathrm{CH}_{2} \mathrm{Cl}_{2} ;$ h) MeNHCHO, PPTS, hydroquinone, MS3A, benzene, reflux; i) DDQ, $\mathrm{CH}_{2} \mathrm{Cl}_{2},{ }^{t} \mathrm{BuOH}, 1 \mathrm{M}$ phosphate buffer ( $\mathrm{pH}$ 6.0); j) 2,3-di-O-methyl-D-glyceric acid, 2,4,6-trichlorobenzoyl chloride, $\mathrm{Et}_{3} \mathrm{~N}$, DMAP, benzene; k) ${ }^{n} \mathrm{Bu}_{4} \mathrm{NF}, \mathrm{AcOH}$, THF.

Finally, condensation of $\mathbf{2 6}$ with 2,3-di-O-methyl-D-glyceric acid using the Yamaguchi procedure and removal of the $C 3$ TBDPS group by TBAF along with $\mathrm{AcOH}$ furnished mycalolide $\mathrm{B}$ (1) in analytically pure form. The ${ }^{1} \mathrm{H}$ and ${ }^{13} \mathrm{C}$ NMR spectra of the synthetic mycalolide $B$ are consistent with those of the natural product, along with its specific optical rotation $\left\{[\alpha]_{D}{ }^{25}-55\right.$ (c 0.55, A cross metathesis / macrolactonization approach was examined next (Scheme 4). Condensation of carboxylic acid 3 with 2,2,2-trichloroethanol provided trichloroethyl (TCE) ester 18. Triethylsilyl (TES) protection of the secondary alcohol in $\mathbf{4}$ gave silyl ether 19. In contrast to the RCM reactions, treatment of 18 and 19 (1.2 equiv.) with $20 \mathrm{~mol} \%$ of $H G-/ l$ catalyst (17b) in refluxing $\mathrm{CH}_{2} \mathrm{Cl}_{2}$ (13 $\mathrm{mM}$ for 18 ) preferentially yielded the coupling product 20 in an $E$-selective manner $(E / Z=5.0: 1) .{ }^{[27]}$ 
$\left.\mathrm{CHCl}_{3}\right)$ for synthetic $1 ;[\alpha]_{\mathrm{D}}-53\left(c \mathrm{c} .3, \mathrm{CHCl}_{3}\right)$ for natural $\left.\mathbf{1}^{[1 \mathrm{a}]}\right\}$. Synthetic 1 was also identical to an authentic sample on the basis of TLC and HPLC analysis. In addition, oxidation of the secondary alcohol in $\mathbf{2 6}$ with Dess-Martin periodinane gave authentic TBDPS-protected mycalolide $A,{ }^{[16]}$ and removal of the TBDPS group afforded mycalolide A (2), whose ${ }^{1} \mathrm{H}$ NMR data coincided with the reported one. ${ }^{[1 a, 16]}$

In summary, we have developed a convergent approach for the synthesis of the tris-oxazole marine macrolides, and completed total synthesis of mycalolides A and B. The key elements in this synthesis include the use of RCM / cross metathesis and esterification as fragment coupling technology for complex building blocks that possess a variety of functional groups. Further studies on the synthesis and structure-activity relationships of mycalolides and related actin-targeting natural products, as well as on their mechanisms of action, are currently underway.

Keywords: marine natural product $\bullet$ total synthesis $\bullet$ olefin metathesis $\cdot$ macrolactonization

[1] a) N. Fusetani, K. Yasumuro, S. Matsunaga, K. Hashimoto, Tetrahedron Lett. 1989, 30, 2809-2812; b) S. Matsunaga, P. Liu, C. A. Celatka, J. S. Panek, N. Fusetani, J. Am. Chem. Soc. 1999, 121, 56055606; c) S. Wada, S. Matsunaga, S. Saito, N. Fusetani, S. Watabe, J. Biochem. 1998, 123, 946-952; d) P. Phuwapraisirisan, S. Matsunaga, R. W. M. van Soest, N. Fusetani, J. Nat. Prod. 2002, 65, 942-943; e) S. Tsukamoto, K. Koimaru, T. Ohta, Mar. Drugs 2005, 3, 29-35.

[2] a) S. Matsunaga, T. Sugawara, N. Fusetani, J. Nat. Prod. 1998, 61, 1164-1167; b) M. A. Rashid, K. R. Gustafson, J. H. Cardeilina II, M. R. Boyd, J. Nat. Prod. 1995, 58, 1120-1125.

[3] a) M. Hori, S. Saito, Y. Shin, H. Ozaki, N. Fusetani, H. Karaki, FEBS Lett. 1993, 322, 151-154; b) S. Saito, S. Watabe, H. Ozaki, N. Fusetani, H. Karaki, J. Biol. Chem. 1994, 269, 29710-29714.

[4] J. A. Roesener, P. J. Scheuer, J. Am. Chem. Soc. 1986, 108, 846-847.

[5] a) S. Matsunaga, N. Fusetani, K. Hashimoto, K. Koseki, M. Noma, H. Noguchi, U. Sankawa, J. Org. Chem. 1989, 54, 1360-1363; b) M. R. Kernan, T. F. Molinski, D. J. Faulkner, J. Org. Chem. 1988, 53, 50145020; c) S. -C. Chung, S. -H. Lee, K. H. Jang, W. Park, J. -E. Jeon, H Oh, J. Shin, K. -B. Oh, Bioorg. Med. Chem. Lett. 2011, 21, 3198-3201.

[6] J. Kobayashi, O. Murata, H. Shigemori, J. Nat. Prod. 1993, 56, 787791.

[7] a) S. Matsunaga, N. Fusetani, J. Hashimoto, J. Am. Chem. Soc. 1986 108, 847-849; b) J. Tanaka, Y. Yan, J. Choi, J. Bai, V. A. Klenchin, I. Rayment, G. Marriott, Proc. Natl. Acad. Sci. U.S.A. 2003, 100, 1385113856.

[8] a) M. Kita, K. Yoneda, Y. Hirayama, K. Yamagishi, Y. Saito, Y. Sugiyama, Y. Miwa, O. Ohno, M. Morita, K. Suenaga, H. Kigoshi, ChemBioChem 2012, 13, 1754-1758; b) O. Ohno, M. Morita, K. Kitamura, T. Teruya, K. Yoneda, M. Kita, H. Kigoshi, K. Suenaga, Bioorg. Med. Chem. Lett. 2013, 23, 1467-1471; c) S. Y. Bae, G. D. Kim, J. Jeon, J. Shin, S. K. Lee, Toxicology in Vitro 2013, 27, 694-699.

[9] Reviews: a) K. Yamada, M. Ojika, H. Kigoshi, K. Suenaga, Nat. Prod. Rep. 2009, 26, 27-43; b) K. Yamada, M. Ojika, H. Kigoshi, K. Suenaga Proc. Jpn. Acad. Ser. B 2010, 86, 176-189; c) M. Kita, H. Kigoshi, Nat Prod. Rep. 2015, 32, 534-542.

[10] a) K. Suenaga, S. Miya, T. Kuroda, T. Handa, K. Kanematsu, A. Sakakura, H. Kigoshi, Tetrahedron Lett. 2004, 45, 5383-5386; b) K. Suenaga, T. Kimura, T. Kuroda, K. Matsui, S. Miya, S. Kuribayashi, A. Sakakura, H. Kigoshi, Tetrahedron 2006, 62, 8278-8290; c) T. Kimura, S. Kuribayashi, T. Sengoku, K. Matsui, S. Ueda, I. Hayakawa, K. Suenaga, H. Kigoshi, Chem. Lett. 2007, 36, 1490-1491; d) K. Kitamura, T. Teruya, T. Kuroda, H. Kigoshi, K. Suenaga, Bioorg. Med. Chem. Lett 2009, 19, 1896-1898; e) K. Kobayashi, Y. Fujii, Y. Hirayama, S.
Kobayashi, I. Hayakawa, H. Kigoshi, Org. Lett. 2012, 14, 1290-1293; f) I. Hayakawa, H. Kigoshi, Heterocycles 2015, 91, 1137-1155.

[11] a) T. Kuroda, K. Suenaga, A. Sakakura, T. Handa, K. Okamoto, H. Kigoshi, Bioconjugate Chem. 2006, 17, 524-529; b) M. Kita, Y. Hirayama, K. Yamagishi, K. Yoneda, R. Fujisawa, H. Kigoshi, J. Am. Chem. Soc. 2012, 134, 20314-20317.

[12] V. A. Klenchin, J. S. Allingham, R. King, J. Tanaka, G. Marriott, I. Rayment, I. Nat. Struct. Biol. 2003, 10, 1058-1063.

[13] J. S. Allingham, J. Tanaka, G. Marriott, I. Rayment, Org. Lett. 2004, 6, 597-599.

[14] M. Kita, H. Oka, A. Usui, T. Ishitsuka, Y. Mogi, H. Watanabe, H. Kigoshi, Tetrahedron 2012, 68, 8753-8760.

[15] Review: K. S. Yeung, I. Paterson, Angew. Chem. 2002, 114, 48264847; Angew. Chem. Int. Ed. 2002, 41, 4632-4653.

[16] a) P. Liu, J. S. Panek, J. Am. Chem. Soc. 2000, 122, 1235-1236; b) J. S. Panek, P. Liu, J. Am. Chem. Soc. 2000, 122, 11090-11097.

[17] a) S. K. Chattopadhyay, G. Pattenden, Tetrahedron Lett. 1998, 39 6095-6098; b) S. K. Chattopadhyay, J. Kempson, A. McNeil, G. Pattenden, M. Reader, D. E. Rippon, D. Waite, J. Chem. Soc. Perkin Trans. 1 2000, 2415-2428; c) S. K. Chattopadhyay, G. Pattenden, J. Chem. Soc. Perkin Trans. 1 2000, 2429-2454; d) G. Pattenden, N. J. Ashweek, C. A. G. Baker-Glenn, G. M. Walker, J. G. K. Yee, Angew. Chem. 2007, 119, 4437-4441; Angew. Chem. Int. Ed. 2007, 46, 43594363; e) G. Pattenden, N. J. Ashweek, C. A. G. Baker-Glenn, J. Kempson, G, M. Walker, J. G. K. Yee, Org. Biomol. Chem. 2008, 6, 1478-1497.

[18] M. Kita, H. Watanabe, T. Ishitsuka, Y. Mogi, H. Kigoshi, Tetrahedron Lett. 2010, 51, 4882-4885.

[19] a) P. R. Blakemore, W. J. Cole, P. J. Kocienski, A. Morley, Synlett, 1998, 26-28; b) P. R. Blakemore, J. Chem. Soc. Perkin Trans. 12002, 2563-2585.

[20] H. Kigoshi, K. Suenaga, T. Mutou, T. Ishigaki, T. Atsumi, H. Ishiwata, A. Sakakura, T. Ogawa, M. Ojika, K. Yamada, J. Org. Chem. 1996, 61, 5326-5351.

[21] 22R-12 was converted to the $22 S$ isomer in $64 \%$ yield (2 steps). See the Supporting Information for details.

[22] a) I. Shiina, M. Kubota, R. Ibuka, Tetrahedron Lett. 2002, 43, 75357539; b) I. Shiina, M. Kubota, H. Oshiumi, M. Hashizume, J. Org. Chem. 2004, 69, 1822-1825.

[23] a) M. Scholl, S. Ding, C. W. Lee, R. H. Grubbs, Org. Lett. 1999, 1, 953956; b) A. K. Chatterjee, T. -L. Choi, D. P. Sanders, R. H. Grubbs, J. Am. Chem. Soc. 2003, 125, 11360-11370.

[24] a) J. S. Kingsbury, J. P. A. Harrity, P. J. Bonitatebus, A. H. Hoveyda, J. Am. Chem. Soc. 1999, 121, 791-799; b) S. B. Garber, J. S. Kingsbury B. L. Gray, A. H. Hoveyda, J. Am. Chem. Soc. 2000, 122, 8168-8179.

[25] a) K. Grela, S. Harutyunyan, A. Michrowska, Angew. Chem. 2002, 114 4210-4212; Angew. Chem. Int. Ed. 2002, 41, 4038-4040; b) A. Michrowska, R. Bujok, S. Harutyunyan, V. Sashuk, G. Dolgonos, K. Grela. J. Am. Chem. Soc. 2004, 126, 9318-9325.

[26] Z. -Y. Zhan, WO Patent 2007003135, 2007.

[27] A homodimer of 19 was also formed (E/Z 4/1, 8\%), which could also be subjected to cross metathesis with 18 , or converted to 20 by ethenolysis. See the Supporting Information for details.

[28] J. Inanaga, K. Hirata, H. Saeki, T. Kabuki, M. Yamaguchi, Bull. Chem Soc. Jpn. 1979, 52, 1989-1993.

[29] For example, sodium borohydride reduction of 22 at $0{ }^{\circ} \mathrm{C}$ preferred the 1,4-reduction of conjugated ketone (quant.), and sodium trimethoxyborohydride reduction at room temperature resulted in a mixture of unreacted conjugated ketone $(45 \%)$ and $\alpha, \beta$-saturated $C 7$ alcohol (36\%), while the hemiacetal was completely converted to 1,4diol in both cases.

[30] To avoid the formation of several $\beta$-eliminated products including the demethoxy, deacetoxy, and de-DMPMOM ether groups, the reaction was stopped before the completion, and unreacted aldehyde $\mathbf{2 5}$ was recovered $(33 \%)$. 


\section{COMMUNICATION}

An asymmetric total synthesis of the tris-oxazole macrolides, mycalolides $A$ and $B$, is described. This synthesis involves the convergent assembly of C1-C19 tris-oxazole and C20-C35 side-chain segments through the use of olefin metathesis and esterification as key steps.

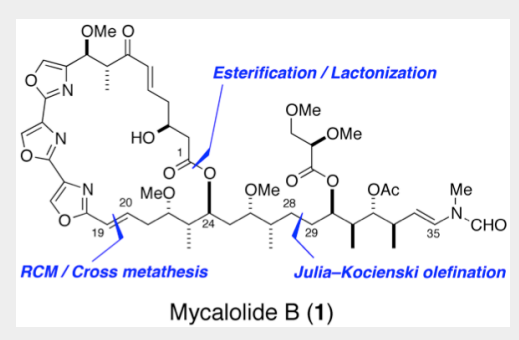

Masaki Kita,* Hirotaka Oka, Akihiro

Usui, Tomoya Ishitsuka, Yuzo Mogi, Hidekazu Watanabe, Masaki Tsunoda, Hideo Kigoshi*

Page No. - Page No.

Total Synthesis of Mycalolides A and B via Olefin Metathesis 